\title{
Age-related trends in cardiometabolic disease among adults with cerebral palsy
}

\author{
MARK D PETERSON ${ }^{1,2}$ (D) | NEIL KAMDAR ${ }^{2,3}$ | EDWARD A HURVITZ
}

1 Department of Physical Medicine and Rehabilitation, Michigan Medicine, University of Michigan, Ann Arbor, Ml; 2 Institute for Healthcare Policy and Innovation, Michigan Medicine, University of Michigan, Ann Arbor, Ml; 3 Department of Obstetrics and Gynecology, Michigan Medicine, University of Michigan, Ann Arbor, MI, USA.

Correspondence to Mark D Peterson, Department of Physical Medicine and Rehabilitation, University of Michigan Hospital and Health Systems, 325 E Eisenhower Parkway, Suite 300 , Ann Arbor, Ml 48108, USA. E-mail: mdpeterz@med.umich.edu

This article is commented on by McPhee on pages 390-391 of this issue.

\section{PUBLICATION DATA}

Accepted for publication 27th February

2018.

Published online 27 April 2018.

\section{ABBREVIATION}

ICD-9-CM International Classification of Diseases, Ninth Revision, Clinical Modification
AIM To examine the longitudinal trends of cardiometabolic diseases in a large sample of adults with cerebral palsy (CP).

METHOD The Optum Clinformatics Data Mart is a de-identified nationwide claims database of beneficiaries from a single private payer. Beneficiaries were included if they had an International Classification of Diseases, Ninth Revision, Clinical Modification code for a diagnosis of CP. Adults with at least 3 years of continuous enrollment on a single plan between 2002 and 2009 were included in the final analyses $(n=2659)$. We examined the longitudinal trends of incident diabetes mellitus, hypercholesterolemia, hypertension, cardiac dysrhythmias, and atherosclerosis, stratified by age categories: 18 to 39 years, 40 to 59 years, and 60 years and over. Kaplan-Meier product-limit survival curves were compared across age categories for each of the cardiometabolic outcomes, and a Cox proportional hazards regression was run to determine adjusted hazard ratios.

RESULTS The cumulative incidence of each of the cardiometabolic diseases ranged from $6.0 \%$ for atherosclerosis to $34.4 \%$ for hypercholesterolemia at 3 years and over. Risk-adjusted Cox proportional hazard models revealed that age was a robust predictor of survival for each outcome, with higher hazard ratio ranges in middle age (hazard ratio 1.41-2.72) and older adults (hazard ratio 2.20-5.93) compared with young adults.

INTERPRETATION Adults with CP have high rates of cardiometabolic diseases; and diseasefree survival shortens significantly with higher ages.
Cerebral palsy (CP) is the most common pediatric-onset physical disability, with an estimated prevalence ranging from 2.6 to 3.1 cases per 1000 live births in the USA. ${ }^{1}$ Many individuals with mild to moderate CP can expect near-normal life expectancies, ${ }^{2}$ yet there is a lack of clinical follow-up for patients after they transition from pediatric to adult primary care, and insufficient cohort data to track patients with CP longitudinally. ${ }^{3}$ The vast majority of clinical research has come from small single-center interventions, and is centrally focused on symptom management for children or adolescents with CP.

Despite the shortage of research to track lifelong health and chronic disease trajectories in this population, there is ample evidence demonstrating that individuals with CP have significant and progressive motor impairment, unhealthy body composition, and excessive sedentary behavior profiles, all of which increase with age. ${ }^{4-6}$ These factors place adults with $\mathrm{CP}$ at a heightened risk for secondary chronic conditions ${ }^{7}$ that further worsen functional status and quality of life, as well as leading to decreased independence. ${ }^{8}$ Indeed, CP represents a significant lifetime disability for individuals, their families, and caregivers, and is associated with increased prevalent cardiometabolic diseases, ${ }^{9}$ chronic multimorbidity, ${ }^{10}$ and a shortened life expectancy. ${ }^{11}$ However, what remains to be determined are the age-related trajectories of cardiometabolic diseases among adults with CP. The objectives of this study were therefore to build upon previous findings by analyzing longitudinal trends and disease-free survival of cardiometabolic diseases (e.g. diabetes, hypertension, atherosclerosis) among adult beneficiaries with CP within a managed-care network of enrollees throughout the USA.

\section{METHOD}

\section{Data source}

The Clinformatics Data Mart Database (OptumInsight, Eden Prairie, MN, USA), is a de-identified nationwide claims database of all beneficiaries from a single private payer. These data comprise all enrollees who had medical and pharmacy insurance coverage at any time between 1st January 2001 and 31st December 2014; a total of 58800802 unique patients. Data are organized by a specific patient identification number, which ensures longitudinal follow-up even if there were changes in plan details or 
gaps in insurance coverage, as previously described. ${ }^{12}$ The data set includes information on medical claims for all conditions for the enrollees as well as demographic information. This database has been previously used to investigate other conditions and their complications, including other neurological, ${ }^{12}$ urological, ${ }^{13}$ and metabolic ${ }^{14}$ conditions. Since the data were de-identified, the University of Michigan Institutional Review Board approved this as a nonregulated study.

\section{Sample selection}

We obtained access to data for all enrollees with CP, aged at least 18 years, during the period from 2001 to 2014. Enrollees were included in the data set if they had an International Classification of Diseases, Ninth Revision, Clinical Modification (ICD-9-CM) code for a CP diagnosis (ICD-9-CM codes 343 and 333.71) (all ICD-9 codes are provided in Table I). Individuals with pre-existing cardiometabolic disease (at least one diagnosis of cardiometabolic disease in the $3 \mathrm{mo}$ preceding the index diagnosis of $\mathrm{CP}$ ) were excluded, as were those with noncontinuous enrollment, and those younger than 18 years of age at the time of index CP diagnosis. Enrollees with at least 3 years of continuous enrollment on a single plan from the index diagnosis of CP, between 2002 and 2009, were included in the final analyses $(n=2659)$. A sensitivity analysis was conducted for two reasons: (1) we evaluated the sample size at 3 months, 6 months, and 12 months before the index diagnosis for continuous enrollment and proportion with previous disease diagnoses; and (2) we evaluated 3 years, 4 years, and 5 years of continuous enrollment on a single plan for follow-up post-index CP diagnosis to determine the appropriate sample for final analysis.

\section{Covariates}

Enrollee information included as covariates was limited to the available socio-demographic data provided in the

\begin{tabular}{lc}
\hline $\begin{array}{l}\text { Table I: International Classification of Diseases, Ninth Revision (ICD-9) } \\
\text { codes for identifying cerebral palsy (CP) and primary cardiometabolic } \\
\text { diseases/conditions }\end{array}$ \\
\hline Diseases & \\
\hline Primary defining disease & \\
Infantile CP & 343 \\
Congenital diplegia & 343.0 \\
Congenital hemiplegia & 343.1 \\
Congenital monoplegia & 343.3 \\
Infantile hemiplegia & 343.4 \\
Other specified infantile CP & 343.8 \\
Other and unspecified CPa & 343.9 \\
Athetoid CP & 333.71 \\
Outcomes: cardiometabolic diseases/conditions & \\
Diabetes mellitus & 250 \\
Hypercholesterolemia & 272 \\
Hypertension & 401 \\
Cardiac dysrhythmias & 402 \\
Atherosclerosis & 440 \\
\hline
\end{tabular}

a Other $\mathrm{CP}$ include mixed $\mathrm{CP}$ and spastic monoplegia.

\section{What this paper adds}

- Adults with cerebral palsy have high rates of cardiometabolic diseases.

- Disease-free survival of all cardiometabolic diseases shortens significantly with higher ages.

- The highest rates were for hypercholesterolemia and hypertension.

insurance claim. Enrollee demographic information for sex, ethnic group (white, black, Latino, Asian, other), education level (less than high school, high school diploma, some college, college diploma, or advanced degree), and household net worth (0 to $<$ US\$40 000, US\$40000 to $<$ US\$50 000, US\$50 000 to $<$ US\$60 000, US\$60 000 to $<$ US\$75 000 to $<$ US\$100 000, or $\geq$ US\$100 000) were included. Age was categorized as young $(18-<40 y)$, middle-aged $(40$ $<60 \mathrm{y})$, and older $(\geq 60 \mathrm{y})$ adults.

\section{Outcomes}

The study outcomes were diagnoses of any of the following five cardiometabolic diseases/conditions, using ICD-9CM codes (all ICD-9 codes are provided in Table I), after the CP diagnosis/index date: (1) diabetes mellitus, (2) hypercholesterolemia, (3) hypertension, (4) cardiac dysrhythmias, and (5) atherosclerosis. These conditions were selected in accordance with guidance from the literature pertaining to cardiometabolic diseases in adults and adults with disabilities, ${ }^{15,16}$ and availability of the diagnosis within the claims data.

\section{Statistical analysis}

All analyses were performed using SAS version 9.4 (SAS Institute, Cary, NC, USA). Enrollee characteristics were summarized using means (standard deviations [SDs]) for continuous variables, and frequencies and percentages for categorical variables. Bivariate analysis was conducted using $\chi^{2}$ tests or Fisher's exact test in the case of small sample size for categorical variables, or an analysis of variance or non-parametric tests for continuous variables. The analysis of variance assumptions required us to check continuous variables based on quantile-quantile plots, assessing degrees of skew and kurtosis, and evaluating whether normally distributed errors were evident. We also reviewed the histogram of the distribution for visual inspection for any strong departures from normality. Event-free survival was estimated for young, middle-aged, and older adults using the Kaplan-Meier product-limit survival curves for at least 3 years of follow-up. Cumulative incidence was determined as 1 minus the survival probability. Cox proportional hazards regression was used to estimate adjusted hazard ratios with the dependent variable as the time to first occurrence for each of the six cardiometabolic outcomes. Proportional hazards assumption was assessed using log-rank tests and evaluation of the Kaplan-Meier product-limit survival curves. Adjusted failure rates were estimated using the Cox model. Patients were right censored at the date they discontinued enrollment or at the end of the follow-up period in the database (i.e. 31st December 2014). We conducted a sensitivity analysis by fitting Cox 
regression models without household income to examine whether the significance of adjusted hazard ratios changed as a result of its omission from our final models. For each cardiometabolic outcome, we determined that household income did not change overall significance; therefore, it seems final model estimates were sufficiently unbiased and determined income was an important socio-demographic covariate to include in the adjustment. A two-tailed $p$ value of $<0.05$ was used as the threshold for statistical significance in all tests.

\section{RESULTS}

A total of 2659 adults with CP met the inclusion criteria. The mean time in the plan for eligible enrollees was 7 years plus or minus 2 years 10 months, ranging from 3 years (inclusion criterion) to 11 years (maximum available data from 2001-2011). The sample included 1285 females (48\%); among those with known ethnic group, there were 1996 whites (75.0\%), 256 blacks (9.6\%), 204 Hispanics (7.7\%), and 59 Asians (2.2\%). Of the 2659, 735 enrollees $(27.6 \%)$ came from a household with incomes of more than US\$100,000, and 454 enrollees (17.1\%) had a college diploma or higher education level (presented in Table II).

The cumulative incidence of each of the cardiometabolic diseases in all enrollees ranged from $6.0 \%$ to $34.4 \%$ at 3 years and over, and was $11.6 \%$ for diabetes mellitus, $34.4 \%$ for hypercholesterolemia, $28.9 \%$ for hypertension, $13.2 \%$ for cardiac dysrhythmias, and $6.0 \%$ for atherosclerosis.

Table II: Characteristics of adults with cerebral palsy, ages 18 years and over

\begin{tabular}{lcc}
\hline & $\begin{array}{l}\text { Females } \\
n=1285\end{array}$ & $\begin{array}{c}\text { Males } \\
n=1374\end{array}$ \\
& $36(25,48)$ & $36(25,48)$ \\
\hline Age, $^{\text {a }}$ & $7(5,9)$ & $7(5,9)$ \\
Number of years on health plan & a & \\
Ethnic group, \% & 2.1 & 1.7 \\
Missing & 74.6 & 75.5 \\
White & 10.2 & 9.1 \\
Black & 7.4 & 7.9 \\
Latino & 2.3 & 2.2 \\
Asian & 3.4 & 3.6 \\
Other/unknown & & \\
Education, \% & 2.3 & 1.8 \\
Unknown/missing & 0.5 & 0.4 \\
Less than high school & 24.8 & 28.7 \\
High school diploma & 53.8 & 53.4 \\
Some college & 18.6 & 15.7 \\
College & & \\
Advanced degree & & \\
Household annual income, \% & 27.7 & 27.1 \\
Unknown/missing & 15.5 & 12.3 \\
<US\$40 000 & 5.9 & 6.2 \\
US\$40 000-49 999 & 5.5 & 6.5 \\
US\$50 000-59 999 & 7.7 & 8.7 \\
US\$60 000-74 999 & 11.1 & 10.6 \\
US\$75 000-99 999 & 26.6 & 28.6 \\
>US\$100 000 & & \\
\hline
\end{tabular}

${ }^{a}$ Continuous variables expressed as medians with 25 th and 75 th centiles.
Kaplan-Meier curves for the unadjusted disease-free survival for each of the cardiometabolic outcomes in young, middle-aged, and older adults are shown in Figure 1. Mean disease-free survival rates varied greatly between outcomes and were generally significantly less for middle-aged and older adults compared with young adults. Specifically, disease-free survival (mean \pm standard errors) was 1728.5 plusminus 14.4 days, 1629.5 plus or minus 18.9 days, and 1472.9 plus or minus 33.6 days for diabetes mellitus; 1487.5 plus or minus 21.5 days, 1165.7 plus or minus 26.2 days, and 943.0 plus or minus 34.4 days for hypercholesterolemia; 1553.2 plus or minus 20.7 days, 1243.2 plus or minus 26.6 days, and 960.3 plus or minus 36.6 days for hypertension; 1645.3 plus or minus 17.8 days, 1568.0 plus or minus 20.6 days, and 1452.1 plus or minus 33.0 days for cardiac dysrhythmias; and 1507.0 plus or minus 5.2 days, 1736.2 plus or minus 11.0 days, and 1623.7 plus or minus 22.3 days for atherosclerosis among young, middle-aged, and older adults with CP respectively.

Fully adjusted multivariable survival analyzes demonstrated a significant effect of higher hazard ratios in middle age (hazard ratio 1.41-2.72) and older adults (hazard ratio 2.20-5.93) compared with young adults. Further, riskadjusted Cox proportional hazard models revealed that sex and ethnic group were also associated with various incident outcomes (Tables SI-SV, online supporting information).

\section{DISCUSSION}

We calculated the longitudinal trends and disease-free survival of cardiometabolic diseases and risk factors in a large sample of adults with CP. The principal findings were that adults with CP have high rates of incident cardiometabolic diseases; and that disease-free survival shortens significantly with higher age stratification. Specifically, we determined that the cumulative incidences $(\geq 3 \mathrm{y})$ of type 2 diabetes, hypercholesterolemia, hypertension, cardiac dysrhythmias, and atherosclerosis were between $6 \%$ and $34 \%$ in adults with $\mathrm{CP}$ within a nationwide claims database. The highest rates observed were for hypercholesterolemia and hypertension, at $34.4 \%$ and $28.9 \%$ respectively, which are similar to the lifetime risk of these outcomes in the otherwise healthy, general population without $\mathrm{CP} .{ }^{17}$ It is plausible that the lower rates observed for atherosclerosis may be due in part to the irregularity of clinical cardiovascular screening in the population with CP. Indeed, there is a well-established literature describing the disparities in healthcare access and use among persons with intellectual and physical disabilities, ${ }^{18}$ and particularly affecting preventive health services use and screening rates. With the relatively high incidence for atherosclerosis risk factors described in this study (i.e. hypercholesterolemia), and the additional risk factors related to obesity and decreased physical activity noted elsewhere, ${ }^{19,20}$ the true rate for undetected atherosclerosis in CP is likely much higher. This may also reflect a selection bias towards higher-functioning individuals with $\mathrm{CP}$ and an underrepresentation of 

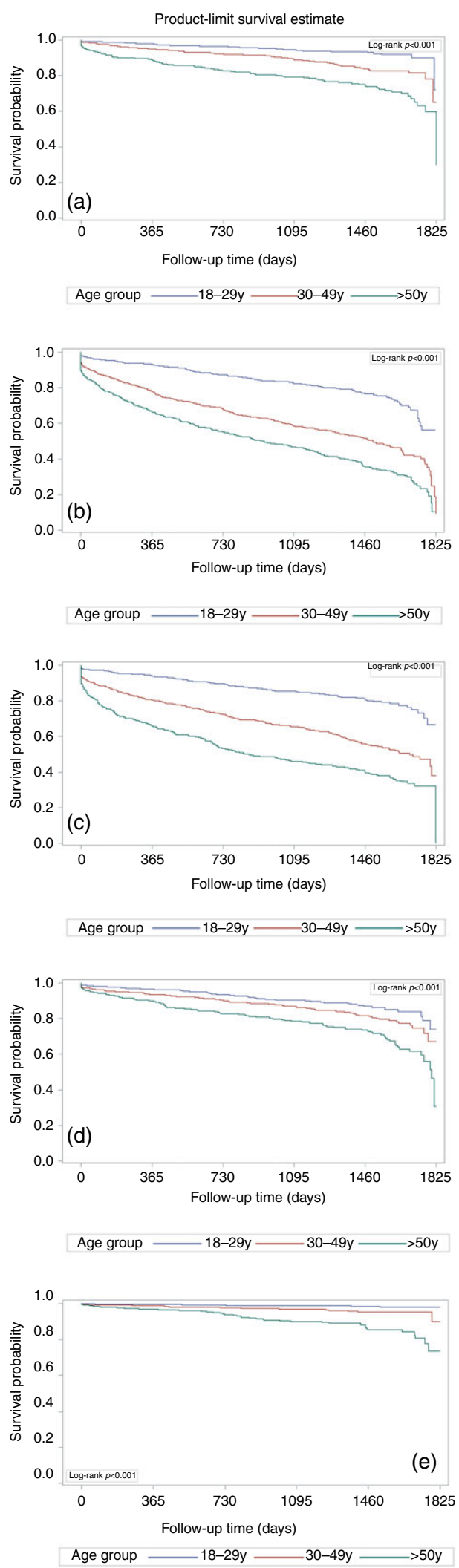

Figure 1: Disease-free survival for young, middle-aged, and older adults and Kaplan-Meier product-limit survival curves, for (a) type 2 diabetes, (b) hypercholesterolemia, (c) hypertension, (d) cardiac dysrhythmias, and (e) atherosclerosis. [Colour figure can be viewed at wileyonlinelibrary.com]. overall cardiometabolic disease burden, as it is plausible that many individuals with more severe physical and intellectual disabilities or complex diagnoses may be using social healthcare coverage. With the emergence of and improvements in novel and non-invasive methods of screening for subclinical atherosclerotic plaques (e.g. highresolution ultrasound can provide images of the arterial wall and plaques at a resolution of $0.2 \mathrm{~mm},{ }^{21}$ as well as intima-media thickness), ${ }^{19}$ future efforts to encourage adoptions of these measurements as a feature of standard clinical care for individuals with $\mathrm{CP}$ are certainly warranted.

Nevertheless, these findings raise critical questions about preventable cardiometabolic health complications in $\mathrm{CP}$ through the lifespan. We and others have proposed a rationale for development of registries to better understand and prevent age-related chronic disease risk in the CP population; ${ }^{5,8,22}$ however, this is the first study to examine the longitudinal trends and disease-free survival of primary cardiometabolic diseases among adults with CP. Based on these findings and those of other recent reports showing increased risk of prevalent chronic cardiometabolic conditions and other non-communicable diseases among adults with CP, ${ }^{19,20,23}$ future efforts are needed not only to better understand the healthcare burden associated with these conditions in $\mathrm{CP}$, but, more importantly, to facilitate the development of appropriate clinical screening algorithms and design of early behavioral interventions to reduce risk of disease onset/progression in this population.

Among individuals with $\mathrm{CP}$, many more deaths are attributed to diseases of the circulatory and respiratory systems compared with the general population. ${ }^{24} \mathrm{~A}$ recent analysis indicated that the mortality rate of orally fed adults with $\mathrm{CP}$ has increased over the past 30 years, in contrast to a decline in mortality rates of the general population. ${ }^{25}$ The factors contributing to this trend have not been thoroughly investigated; however, records reveal that mortality caused by ischemic heart disease and cancer is higher among adults with $\mathrm{CP},{ }^{24}$ as is the risk for incident stroke. ${ }^{26}$ There is substantial evidence that individuals with CP have lower cardiovascular fitness, less muscle mass, increased inter- and intramuscular fat deposition, diminished bone density and increased marrow adiposity, and reduced functional reserve throughout childhood and into adulthood. $^{4-6,27-29}$ These factors place individuals with CP at a heightened risk for secondary health concerns such as accelerated functional losses, early sarcopenia, and obesityrelated cardiometabolic diseases., ${ }^{9,22}$ Yet, despite the overwhelming attention and evidence about function and participation changes among individuals with CP throughout the lifespan, there has been a complete paucity of information about longitudinal changes to cardiometabolic health status in this population. McPhee et al. recently demonstrated that age was significantly associated with decreased endothelial function and arterial stiffness in CP, independent of central adiposity and mobility status. ${ }^{19}$ 
Their findings support those of ours and others, which indicate that adults with CP have an elevated risk of many cardiometabolic conditions. ${ }^{9,20}$ We have also recently demonstrated that the prevalence of multimorbidity among middle-aged adults with CP (40-60y) was nearly $60 \%,{ }^{15}$ which is similar to older adults without CP.

This evidence collectively lends strong support for the need to approach healthcare delivery for persons with $\mathrm{CP}$ within the context of a life-course health development model. ${ }^{30}$ Indeed, chronic health is a set of capacities that evolve over a lifetime and allow or prevent individuals to interact within their environments and achieve well-being. The framework that encompasses clinical care for patients with $\mathrm{CP}$ has been largely confined to issues that arise during childhood and adolescence, with little to no focus on understanding life-course health development. Our findings demonstrate that age is a robust risk factor for incident type 2 diabetes, hypercholesterolemia, hypertension, cardiac dysrhythmias, and atherosclerosis among adults with $\mathrm{CP}$. These five conditions represent the primary risk factors for several leading causes of death in the USA (i.e. diabetes, heart disease, and stroke), yet there are various other important age-related health outcomes that have yet to receive adequate attention in the $\mathrm{CP}$ population. Thus, future research is needed to better describe the pattern of age-related trajectories for other common, non-communicable diseases in $\mathrm{CP}$, such as cancer, Alzheimer disease, depression and other psychiatric disorders, osteoporosis, frailty, etc. Regardless, given the interrelationships between age-related declines in physical and cognitive function, muscle atrophy, and risk for obesity, there is a dire need for early behavioral interventions in this population with a priority focus on supporting lifelong physical activity participation and healthy nutritional habits.

\section{Strengths/limitations}

As with all cohort studies, there are several important limitations to this study. First, we did not include a comparison group for cumulative incidence estimates, as this was not the primary aim of the study. However, a formal statistical comparison with a propensity-matched cohort of typically developed adults would provide subsequent support for altered risk patterns in this population. Second, we cannot rule out time-varying confounding since baseline measurements of all covariates were included in our final models. We were unable to determine whether other competing risks or unmeasured confounding (i.e. other risk factors [e.g. smoking], protective factors [e.g. physical activity], or existing diseases [e.g. cancer]) may have influenced the observed survival trajectories. Third, as with any long-term prospective study, losses to follow-up may have resulted in an underestimation of the true association if individuals who were sicker or more impaired were more likely to drop out. Lastly, our sample included adults with CP from a nationwide claims database of all beneficiaries from a single private payer. Therefore, our lack of an association between low socio-economic status indices with incident cardiometabolic outcomes may have been caused by an underrepresentation of adults with CP having lower socio-economic status. Future studies are certainly needed to examine the extent to which disparities exist across federal healthcare-covered versus privately insured individuals with CP. Despite these limitations, this study has various strengths. Most notably, this is the first study to examine changes in primary cardiometabolic health outcomes in a large, nationally representative sample of adults in the USA with CP. This is particularly important since adults with $\mathrm{CP}$ represent a growing population with unique and poorly understood clinical and preventive healthcare needs.

\section{CONCLUSIONS}

The cumulative incidence $(\geq 3 \mathrm{y})$ of cardiometabolic diseases in adults with CP ranged from $6.0 \%$ to $34.4 \%$, and was $11.6 \%$ for diabetes mellitus, $34.4 \%$ for hypercholesterolemia, $28.9 \%$ for hypertension, $13.2 \%$ for cardiac dysrhythmias, and $6.0 \%$ for atherosclerosis. Risk-adjusted Cox proportional hazard models revealed that age was a robust predictor of survival for each outcome, with higher hazard ratio ranges in middle age (hazard ratio 1.41-2.72) and older adults (hazard ratio 2.20-5.93) compared with young adults. Therefore, adults with $\mathrm{CP}$ have high rates of incident cardiometabolic diseases; and disease-free survival shortens significantly with higher age. On the basis of these findings, future efforts are needed not only to better understand the healthcare burden associated with these conditions in CP, but more importantly to facilitate the development of appropriate clinical screening algorithms and design of early behavioral interventions to reduce risk of disease onset/progression in this high-risk population.

\section{ACKN OWLEDGEMENTS}

We acknowledge the expertise and assistance of Ryan Jakubowski in creating the manuscript figure. MDP is funded by the National Institutes of Health (1KO1 HD074706) and the National Institute on Disability, Independent Living, and Rehabilitation Research (90IF0102-01). The authors have stated that they had no interests that could be perceived as posing a conflict or bias.

\section{SUPPORTING INFORMATION}

The following additional material may be found online:

Table SI: Cox proportional hazards regression for independent predictors of type 2 diabetes

Table SII: Cox proportional hazards regression for independent predictors of hypercholesterolemia

Table SIII: Cox proportional hazards regression for independent predictors of hypertension

Table SIV: Cox proportional hazards regression for independent predictors of cardiac dysrhythmias

Table SV: Cox proportional hazards regression for independent predictors of atherosclerosis 


\section{REFERENCES}

1. Maenner MJ, Blumberg SJ, Kogan MD, Christensen D, Yeargin-Allsopp M, Schieve LA. Prevalence of cerebral palsy and intellectual disability among children identified in two U.S. National Surveys, 2011-2013. Ann Epidemiol 2016; 26: 222-6.

2. Hutton JL. Outcome in cerebral palsy: life-expectancy. Paediatr Child Health 2008; 18: 419-22.

3. Oskoui M. Growing up with cerebral palsy: contemporary challenges of healthcare transition. Can $7 \mathrm{Neurol} \mathrm{Sci}$ 2012; 39: 23-5.

4. Moreau NG, Li L, Geaghan JP, Damiano DL. Fatigue resistance during a voluntary performance task is associated with lower levels of mobility in cerebral palsy. Arch Phys Med Rehabil 2008; 89: 2011-16.

5. Shortland A. Muscle deficits in cerebral palsy and early loss of mobility: can we learn something from our elders? Dev Med Child Neurol 2009; 51(Suppl 4): 59-63.

6. Peterson MD, Zhang P, Haapala HJ, Wang SC, Hurvitz EA. Greater adipose tissue distribution and diminished spinal musculoskeletal density in adults with cerebral palsy. Arch Phys Med Rehabil 2015; 96: 1828-33.

7. Ryan JM, Allen E, Gormley J, Hurvitz EA, Peterson MD. The risk of non-communicable diseases among people with cerebral palsy: a scoping review of the literature. Dev Med Child Neurol 24 Mar 2018; https://doi. org/10.1111/dmcn.13737. [Epub ahead of print].

8. Peterson MD, Gordon PM, Hurvitz EA, Burant CF. Secondary muscle pathology and metabolic dysregulation in adults with cerebral palsy. Am 7 Physiol Endocrinol Metab 2012; 303: E1085-93.

9. Peterson MD, Ryan JM, Hurvitz EA, Mahmoudi E. Chronic conditions in adults with cerebral palsy. $7 A M A$ 2015; 314: 2303-5.

10. Cremer N, Hurvitz EA, Peterson MD. Multimorbidity in middle-aged adults with cerebral palsy. Am $7 \mathrm{Med}$ 2017; 130: 744.e9-15.
11. Kruse M, Michelsen SI, Flachs EM, Brønnum-Hansen H, Madsen M, Uldall P. Lifetime costs of cerebral palsy. Dev Med Child Neurol 2009; 51: 622-8.

12. Wilkinson DA, Johnson K, Garton HJ, Muraszko KM, Maher CO. Trends in surgical treatment of Chiari malformation type I in the United States. 7 Neurosurg Pediatr 2017; 19: 208-16.

13. Borza T, Jacobs BL, Montgomery JS, et al. No differences in population-based readmissions after open and robotic-assisted cystectomy: implications for post-discharge care. Urology 2017; 104: 77-83.

14. Stem MS, Blachley TS, Shtein RM, Herman WH, Gardner TW, Stein JD. Impact of diagnosing diabetic complications on future hemoglobin A1c levels. 7 Diabetes Complications 2016; 30: 323-8.

15. Quiñones AR, Markwardt S, Botoseneanu A. Multimorbidity combinations and disability in older adults. 7 Gerontol A Biol Sci Med Sci 2016; 71: 823-30.

16. Espeland MA, Crimmins EM, Grossardt BR, et al. Clinical trials targeting aging and age-related multimorbidity. 7 Gerontol A Biol Sci Med Sci 2017; 72: 355-61.

17. Benjamin EJ, Blaha MJ, Chiuve SE, et al. Heart disease and stroke statistics - 2017 update: a report from the American Heart Association. Circulation 2017; 135: e146-603.

18. Meade MA, Mahmoudi E, Lee SY. The intersection of disability and healthcare disparities: a conceptual framework. Disabil Rehabil 2015; 37: 632-41.

19. McPhee PG, Gorter JW, Cotie LM, Timmons BW, Bentley T, MacDonald MJ. Associations of non-invasive measures of arterial structure and function, and traditional indicators of cardiovascular risk in adults with cerebral palsy. Atherosclerosis 2015; 243: 462-5.

20. Ryan JM, Crowley VE, Hensey O, McGahey A, Gormley $\mathrm{J}$. Waist circumference provides an indication of numerous cardiometabolic risk factors in adults with cerebral palsy. Arch Phys Med Rehabil 2014; 95: 1540-6.
21. Nicolaides A, Panayiotou AG. Screening for atherosclerotic cardiovascular risk using ultrasound. $7 \mathrm{Am}$ Coll Cardiol 2016; 67: 1275-7.

22. Peterson MD, Gordon PM, Hurvitz EA. Chronic disease risk among adults with cerebral palsy: the role of premature sarcopoenia, obesity and sedentary behaviour. Obes Rev 2013; 14: 171-82.

23. Whitney DG, Hurvitz EA, Ryan JM, et al. Noncommunicable disease and multimorbidity in young adults with cerebral palsy. Clin Epidemiol. Forthcoming; in press.

24. Strauss D, Cable W, Shavelle R. Causes of excess mortality in cerebral palsy. Dev Med Child Neurol 1999; 41: $580-5$.

25. Brooks JC, Strauss DJ, Shavelle RM, Tran LM, Rosenbloom L, Wu YW. Recent trends in cerebral palsy survival. Part I: period and cohort effects. Dev Med Child Neurol 2014; 56: 1059-64.

26. Wu CW, Huang SW, Lin JW, Liou TH, Chou LC, Lin HW. Risk of stroke among patients with cerebral palsy: a population-based cohort study. Dev Med Cbild Neurol 2017; 59: 52-6.

27. Rose J, McGill KC. Neuromuscular activation and motor-unit firing characteristics in cerebral palsy. Dev Med Child Neurol 2005; 47: 329-36.

28. Whitney DG, Singh H, Miller F, et al. Cortical bone deficit and fat infiltration of bone marrow and skeletal muscle in ambulatory children with mild spastic cerebral palsy. Bone 2017; 94: 90-7.

29. Barber LA, Read F, Lovatt Stern J, Lichtwark G, Boyd RN. Medial gastrocnemius muscle volume in ambulant children with unilateral and bilateral cerebral palsy aged 2 to 9 years. Dev Med Child Neurol 2016; 58: 1146-52.

30. Palisano RJ, Di Rezze B, Stewart D, et al. Life course health development of individuals with neurodevelopmental conditions. Dev Med Child Neurol 2017; 59: 470- 


\section{RESUMEN}

\section{TENDENCIAS RELACIONADAS CON LA EDAD EN LA ENFERMEDAD CARDIO-METABÓLICA EN ADULTOS CON PARÁLISIS CEREBRAL}

OBJETIVO Examinar las tendencias longitudinales de las enfermedades cardio-metabólicas en una gran muestra de adultos con parálisis cerebral (PC).

MÉTODO El Data Mart de Optum Clinformatics es una base de datos de reclamaciones nacional anónima de beneficiarios de un único proveedor de servicios de salud privado. Se incluyeron los beneficiarios si tenían un Código de Clasificación Internacional de Enfermedades, Novena Revisión, Modificación Clínica para un diagnóstico de PC. Los adultos con al menos 3 años de inscripción continua en un solo plan entre 2002 y 2009 se incluyeron en los análisis finales ( $n=2659$ ). Examinamos las tendencias longitudinales de diabetes mellitus incidente, hipercolesterolemia, hipertensión, disritmias cardíacas y aterosclerosis, estratificadas por categorías de edad: de 18 a 39 años, de 40 a 59 años y mayores de 60 años. Se compararon las curvas de supervivencia del límite de producto de Kaplan-Meier para cada categoría de edad para cada resultado cardio-metabólico, y se realizó una regresión de riesgos proporcionales de Cox para determinar los cocientes de riesgo ajustados.

RESULTADOS La incidencia acumulada de cada una de las enfermedades cardio-metabólicas varió del $6.0 \%$ para la aterosclerosis al $34.4 \%$ para la hipercolesterolemia a los 3 años y más. Los modelos de riesgo proporcional de Cox ajustados por riesgo revelaron que la edad era un predictor robusto de supervivencia para cada resultado, con rangos de razón de riesgo más altos en la mediana edad (razón de riesgo 1.41-2.72) y adultos mayores (razón de riesgo 2.20-5.93) en comparación con los adultos jóvenes.

INTERPRETACIÓN Los adultos con PC tienen altas tasas de enfermedades cardio-metabólicas; y la supervivencia libre de enfermedad se acorta significativamente con las edades más altas.

\section{RESUMO}

\section{TENDÊNCIAS RELACIONADAS À IDADE EM DOENÇA CARDIO-METABÓLICA ENTRE ADULTOS COM PARALISIA CEREBRAL}

OBJETIVO Examinar as tendências longitudinais de doenças cardio-metabólicas em uma grande amostra de adultos com paralisia cerebral (PC).

MÉTODO O Optum Clinformatics ${ }^{T M}$ Data Mart é uma base de dados nacional não-identificada de beneficiários de um convênio privado. Os beneficiários foram incluídos se tivessem uma Classificação internacional de doenças, nona revisão, códico de modificação clínica para diagnóstico de PC. Adultos com pelo menos 3 anos de envolvimento contínuo em um único plano entre 2002 e 2009 foram incluídos na análise final ( $n=2659$ ). Examinamos as tendências longitudinais de incidência de diabetes mellitus, hipercolesterolemia, hipertensão, disritmias cardíacas e aterosclerose, estratificadas por categorias etárias: 18 a 39 anos, 40 a 59 anos, e acima de 60 anos. Curvas de sobreviência produto-limite de Kaplan-Meier foram comparadas entre categorias etárias para cada uma das condições cardio-metabólicas, e uma regressão de riscos proporcionais de Cox foi realizada para determinar as taxas ajustadas de risco.

RESULTADOS A incidência cumulativa de cada doença cardio-metabólica variou de $6.0 \%$ para aterosclerose a $34.4 \%$ para hipercolesterolemia em 3 anos ou mais. Os modelos de risco proporcionais de Cox ajustados revelaram que a idade foi um preditor robusto da sobrevivência para cada desfecho, com maior taxa de risco na meia idade (taxa de risco 1.41-2.72) e em adultos mais velhos (taxa de risco 2.20-5.93) em comparação com jovens adultos.

INTERPRETAÇÃO Adultos com PC tem taxas altas de doenças cardio-metabólicas; a sobrevivência sem doenças se reduz significantemente em maiores idades. 